\title{
A orientação profissional como atividade transversal ao currículo escolar
}

\author{
Altemir José Gonçalves Barbosa \\ Universidade Federal de Juiz de Fora \\ Karen Cristina Alves Lamas \\ Universidade São Francisco
}

\begin{abstract}
Resumo
A teorização e a prática em orientação profissional (OP) desenvolveram-se significativamente nas últimas décadas. Porém, parcela significativa das aplicações desse conhecimento na escola não tem acompanhado os desenvolvimentos atuais. Para analisar um projeto de OP transversal ao currículo escolar, avaliou-se a participação dos docentes e as implicações da OP no comportamento vocacional de alunos do segundo ano do ensino médio. Todos os professores foram convidados a participar. A avaliação do projeto foi feita por 69 alunos que responderam a um questionário e a uma escala de atitudes pré e pós-OP. Nem todos os docentes transversalizaram os temas propostos, mas a quantidade dos que fizeram isso aumentou significativamente. Quanto ao comportamento vocacional, constatou-se redução do número de dúvidas sobre profissões a seguir pós-OP. Houve manutenção das demais variáveis analisadas. A OP transversal ao currículo é uma atividade viável, capaz de promover o desenvolvimento dos adolescentes. Estudos adicionais são recomendados.
\end{abstract}

Palavras-chave: escolha profissional; adolescência; prevenção; ensino médio.

\begin{abstract}
Occupational guidance as a cross-curricular school activity. The theory and practice on occupational guidance (OG) have developed significantly in recent decades. However, a significant portion of the applications of this knowledge in school has not followed the current developments. In order to analyze the cross-curricular school OG project, the participation of teachers and the implications of the OG in the vocational behavior of the second year High School students were evaluated. All teachers were invited to participate. The project assessment was made by 69 students who answered a questionnaire and an attitude scale pre and post OG. Not all teachers transversalized the proposed themes, but the amount of who did this has increased significantly. As for the vocational behavior, a reduction in the number of uncertainties about what profession to follow was noted post-test. Other variables were maintained. The cross-curricular school OG is a viable activity, capable of promoting the development of adolescents. Further studies are recommended.

Keywords: occupational choice; adolescent development; prevention; high school.
\end{abstract}

A escolha de uma profissão é uma tarefa de desenvolvimento fundamental para o ser humano. Alguns autores (Jenschke, 2002; Lehman, 1995) afirmam que o desenvolvimento vocacional na juventude ocidental tem o mesmo nível de relevância que o desenvolvimento moral ou físico. As características do processo educacional e a expectativa social tornam a adolescência, no Brasil e em outras culturas, uma fase na qual se deve demonstrar os primeiros interesses profissionais (Bardagi, Arteche, \& Neiva-Silva, 2005).

Muitos adolescentes, em curto espaço de tempo, se já não estão, estarão diante da expectativa de inserção no mundo do trabalho. Um conjunto de representações sobre a sociedade e sobre a posição que nela ocupam servirá de base para a formulação de seus projetos de vida, incluindo o projeto profissional (Parâmetros Curriculares Nacionais, 1998). Cabe à orientação profissional (OP) desmistificar os preconceitos e distorções existentes, evitando que o jovem tome decisões baseadas em fantasias e estereótipos (Bock, 2002; Sparta \& Gomes, 2005), oriundos de informações tendenciosas apresentadas pela mídia, pela sociedade e pelos familiares (Bardagi et al., 2005).

Ao investigar estudantes de escolas públicas e particulares de Porto Alegre (RS), Sparta e Gomes (2005) verificaram que o ingresso na educação superior ainda é a opção mais frequente (86\%) entre os jovens após o ensino médio, independente da classe social. Porém, no Brasil, o contingente de pessoas que não concluem o ensino médio é muito maior que o de concluintes. Além disso, há aqueles, e não são poucos e ainda que fossem não poderiam ser ignorados, que, mesmo concluindo esse nível escolar, não possuem pré-requisitos para ingressar em um curso 
superior, sejam eles referentes aos conhecimentos mínimos necessários e/ou aos recursos financeiros. Assim, a OP deve instigar o jovem a analisar as várias possibilidades do mundo do trabalho, sem se restringir às profissões universitárias, pois as perspectivas de ascensão social e profissional muitas vezes não se reduzem a essas profissões (Ribeiro, 2003).

$\mathrm{O}$ autoconhecimento também tem sido valorizado no processo de orientação desde a década de 1960 (Abade, 2005). É essencial que o orientando tenha conhecimento sobre suas condições, possibilidades e limitações (Sparta, Bardagi, \& Teixeira, 2006), bem como sobre suas expectativas pessoais em relação ao futuro, valores, interesses e aptidões (Bardagi et al., 2005).

Entretanto, a OP nem sempre considerou esses fatores. Até a década de 1950, o Modelo do Traço e Fator norteava esse processo (Abade, 2005; Sparta et al., 2006). A prática era diretiva e baseada na avaliação psicológica, que contava prioritariamente com testes que revelavam as características do orientando, que deveriam ser comparadas posteriormente com as características das profissões (Abade, 2005; Sparta et al., 2006). Esse modelo se tornou insuficiente a partir das mudanças no mundo do trabalho e na concepção de vocação.

Novas proposições para a OP começaram, assim, a se desenvolver, como, a Teoria do Desenvolvimento Vocacional de Donald Super, o aconselhamento não diretivo de Rogers (Abade, 2005), a Teoria Tipológica de Holland, o Modelo de Ativação do Desenvolvimento de Pelletier, a Abordagem Sócio-Histórica de Sílvio e Ana Bock (Sparta, 2003) e a Teoria Sociocognitiva para o Desenvolvimento de Carreira proposta por Lent e colaboradores, em 1994 (Blustein, McWhirter, \& Perry, 2005; Robitschek \& Woodson, 2006). No Brasil, teve grande repercussão a Abordagem Clínica de Bohoslavsky (1993), que exerceu forte influência nas práticas de orientação e pesquisas (Abade, 2005, Sparta, 2003). Mais recentemente, porém, houve o desenvolvimento de novas abordagens que têm proposto uma maior valorização dos processos de aprendizagem envolvidos na escolha (Carvalho, 1995; Sparta, 2003), bem como dos aspectos que favorecem a formação de interesses por atividades profissionais, como a autoeficácia e as experiências de sucesso, ultrapassando a concepção de ajuste pessoa-ambiente como indicador de satisfação profissional e de produtividade (Robitschek \& Woodson, 2006).

Não obstante as diferenças epistemológicas expressivas entre os múltiplos referenciais mencionados no parágrafo anterior, os desenvolvimentos teóricos no campo da OP fizeram, de acordo com Sparta et al. (2006), com que a decisão passasse a ser vista como resultado de um processo contínuo de desenvolvimento e não como um traço isolado, sendo relativizada a preocupação em se obter ao final do processo de orientação uma escolha definitiva. Aos métodos de orientação foram acrescentadas intervenções em grupo, dinâmicas e recursos lúdicos ou artísticos. Os testes psicológicos passaram a ser utilizados como fonte de dados sobre o sujeito, e não sobre sua decisão. Ademais, os instrumentos psicológicos podem ser utilizados para avaliação dos inputs, processos e outputs, da OP, embora, no Brasil, como em diversos países, essa prática raramente seja realizada (Melo-Silva, Lassance, \& Soares, 2004).
Atualmente, entende-se por OP o processo de facilitação da decisão, a partir do reconhecimento, pelo orientando, das relações entre os elementos sociais, familiares e psicológicos que o influenciam (Bardagi et al.; 2005, Noronha, Freitas, \& Ottati, 2003; Sparta et al., 2006). Isso ocorre a partir do aprendizado do processo de escolha que implica autoconhecimento, informação sobre as profissões e a integração desses aspectos em uma síntese, de modo que se construa uma identificação profissional e um projeto de vida, enfatizando a responsabilidade do orientando sobre sua decisão (Sparta et al., 2006). Além desses aspectos, ressalta-se a importância de, na orientação, analisar o trabalho como conceito e fenômeno (Bock, 2002). Seja no contexto clínico ou escolar, esses são os temas abordados, independente do referencial teórico-metodológico (Melo-Silva et al., 2004).

Robitschek e Woodson (2006) afirmam que, apesar das diferentes teorias existentes, a OP, de certa forma, sempre procurou promover as potencialidades humanas. Descrevem várias intervenções que, ao enfatizar os aspectos positivos do funcionamento, auxiliaram os orientandos na escolha da carreira e na promoção da maturidade vocacional, e também nos aspectos não profissionais, favorecendo, por exemplo, a autoestima, a competência social e o desejo de realizações, gerando redução da ansiedade e da depressão.

A OP no contexto escolar, além de ter uma perspectiva preventiva, pode promover saúde, ao facilitar a compreensão e a transformação das relações sociais do indivíduo, além de capacitá-lo para agir de modo a transformar a realidade e superar os obstáculos que dela advêm (Aguiar \& Bock, 1995). A escola, no entanto, não tem dado ênfase à estimulação do comportamento exploratório vocacional (Bardagi, Lassance, \& Paradiso, 2003; Ribeiro, 2003; Sparta \& Gomes, 2005), definido por Jordaan (1963, citado por Sparta, 2003) como um comportamento de resolução de problemas, que busca promover o autoconhecimento e o conhecimento do mundo do trabalho, e nem tem enfatizado o desenvolvimento de projetos profissionais entre os adolescentes por se preocupar demasiadamente com a preparação para o vestibular.

Para Melo-Silva et al. (2004), quando existe, o serviço de OP é implantado por psicólogos ou pedagogos e são realizados mais frequentemente em escolas particulares. Na rede pública, um dos impedimentos para a implantação desse serviço é a falta de profissional especializado, além de problemas emergenciais, como dificuldades de aprendizagem, problemas comportamentais e socioeconômicos, que levam a OP para um segundo plano. Além das barreiras mencionadas pelos autores, é preciso reconhecer que as políticas públicas na área são limitadas, superficiais e incapazes de fomentar de fato a OP nas escolas públicas.

Como alternativa para a falta de atendimento justo e igualitário a todas as pessoas e como forma de superar barreiras sociais e econômicas que podem inibir a escolha da profissão Lent et al. (2002) e Blustein et al. (2005) sugerem que a OP associe a Teoria Sociocognitiva para o Desenvolvimento de Carreira à Teoria Comunitária Emancipatória, proposta por Prilleltensky (1997). O objetivo da primeira não é exclusivamente mudança interna, mas também auxiliar o indivíduo a identificar obstáculos ambientais e enfrentá-los adequadamente. A OP 
numa perspectiva comunitária deve ser realizada em parceria com escolas, pais, empresas e líderes comunitários, e envolver profissionais de psicologia e áreas afins que devem trabalhar de modo a tornar a vida profissional das pessoas mais segura e ativa (Blustein et al., 2005).

Não obstante a possibilidade de a OP favorecer o desenvolvimento vocacional e ético-social, a maioria dos jovens inicia uma atividade ocupacional sem conhecer as várias implicações dessa escolha (Krumboltz,1992, citado por Bardagi et al., 2005). O jovem desconhece, também, as diferentes alternativas de educação superior e de educação profissional (Sparta \& Gomes, 2005). Há evidências empíricas de que os jovens brasileiros não têm sido suficientemente preparados para cumprirem de forma exitosa essa tarefa de desenvolvimento. Bardagi et al. (2003) constataram que $42,7 \%$ dos estudantes, no meio de um curso superior, já tinham pensado em desistir ou mudar de profissão, e 15,9\% ainda demonstravam essa dúvida. Lehman (2005), por exemplo, afirma que 44,5\% da evasão escolar na educação superior são decorrentes de escolhas mal realizadas. Dos jovens que abandonam a faculdade, 30,7\% o fazem por não se adaptarem à estrutura do curso e $13,4 \%$ por insatisfação com a profissão e com o mercado de trabalho.

Os alunos devem começar a pensar em seu futuro profissional mais cedo, para que possam planejar o nível de esforço e habilidades necessárias para alcançar suas metas. O planejamento de carreira também pode ser uma forma de promover a disciplina em sala de aula, à medida que os alunos aprendam a refletir sobre as consequências de suas escolhas e/ou de seus maus comportamentos, e se preocupem com o próprio planejamento. Além disso, quando o aluno recebe auxílio na exploração de carreira e orientação de estudos, a escola passa a ser significativa para ele, no presente e no futuro. (Southern Regional Education Board - SRED, 2005).

De acordo com o SRED (2005), há vários modelos de orientação de estudo e de carreira que podem ser implantados por escolas, tais como: palestras para pais e alunos, sistema professor-consultor, utilização de programas computacionais e informações on-line. Em algumas escolas, a orientação se inicia nos últimos anos do ensino fundamental. E, segundo a avaliação do SRED, 55\% dos alunos que receberam orientação, pelo menos uma vez ao ano para planejar seus estudos e rever suas escolhas, tiveram significativamente mais conquistas que os alunos não participantes do programa de aconselhamento (37\%). Assim, sugere-se que as escolas implantem a OP e orientação de estudos, com o auxílio dos professores para garantir que todos os pais e alunos recebam informações sobre o que fazer para que estes alcancem realização profissional.

A importância da OP dentro da escola tem sido destacada na literatura científica da área. As intervenções em grupo, baseadas no método clínico (Silva \& Birk, 2002; Valore, 2002), geralmente com alunos de ensino médio, têm sido sugeridas. Numa perspectiva educacional, recomenda-se que ela assuma a forma de uma disciplina da grade curricular para estudantes do ensino fundamental (Affonso \& Sposito, 2005), do ensino médio (Souza, Toledo, Martins, \& Vardi, 2004) e, até mesmo, para crianças pré-escolares (Antunes, Castro, Garbulho, \& Oliveira, 2007; Pasqualini, Garbulho, \& Schut, 2004). Há, ainda, sugestões de programas integrados às disciplinas do currículo escolar com a participação dos professores (Jenschke, 2002; Pelletier, 1981; Uvaldo,1995). No entanto, não foram encontradas investigações brasileiras que apresentam e avaliam essa última forma de intervenção.

Implantar a OP como parte do projeto pedagógico, de forma integrada ao currículo escolar, seria um avanço importante para as escolas, principalmente as públicas (Pelletier, 1981). A legislação brasileira, desde 1996, com a Lei 9.394 - Lei de Diretrizes e Bases da Educação Nacional, designa como um dos objetivos do Ensino Médio a preparação básica para o trabalho. Em 1998, o Ministério da Educação estabeleceu que o trabalho deve ser tratado de forma transversal ao currículo, de modo que perpasse as diversas disciplinas da educação básica. A transversalidade se refere à possibilidade de articular, na prática educativa, conhecimentos teoricamente sistematizados (aprender sobre a realidade) com questões realmente vivenciadas e sua transformação, ou seja, transportar para a realidade o conteúdo do currículo escolar: aprender na realidade e da realidade. De acordo com o referencial curricular para o $3^{\circ}$ e $4^{\underline{0}}$ ciclos do Ensino Fundamental, quando utilizadas situações reais, professor e aluno compartilham os mesmos objetivos. E, a partir da definição de um tema, os alunos têm a possibilidade de utilizar os conhecimentos já adquiridos, buscar novas informações e utilizar os recursos oferecidos pelas diversas áreas para ampliar o sentido dado ao conteúdo (Parâmetros Curriculares Nacionais, 1998). Assim, a transversalidade seria um meio de promover as potencialidades dos alunos, preparando-os para a transição escola-trabalho e para os desafios da vida diária, de forma justa e abrangente. Fomenta, também, o papel de agente de mudança social por meio de reflexões sob aspectos críticos e éticos, sobre as implicações sociais que envolvem a suas escolhas (Lassance \& Sparta, 2003).

Uma vez constatada a importância do aconselhamento ocupacional na adolescência e a necessidade e a possibilidade de a escola ter um papel ativo na facilitação de tarefas de desenvolvimento relacionadas ao trabalho, implantou-se uma OP transversal ao currículo escolar para estudantes do ensino médio. Ela adotou o formato de pesquisa com intervenção e foram analisadas a participação dos docentes no processo de transversalização do trabalho e da escolha profissional, bem como as influências da OP no comportamento vocacional dos discentes. No último caso, foram analisadas especificamente as influências do processo nas atitudes em relação à escolha de uma profissão; na segurança e na preparação para realizar essa escolha; na busca de informações sobre profissões; e nas profissões de interesse.

\section{Método}

\section{Participantes}

A proposta de OP transversal ao currículo do ensino médio foi realizada com todos os integrantes do segundo ano $(N=$ 84) de um colégio de aplicação vinculado a uma universidade pública. Contudo, participaram efetivamente do estudo, isto é, responderam aos instrumentos de coleta de dados no pré e póstestes 69 alunos. Desses, $50,7 \%(n=35)$ eram do sexo feminino 
e 49,3\% $(n=34)$ eram do sexo masculino. A idade média em anos foi $16,35(D P=0,59)$.

Quanto aos docentes, todos foram convidados para participar. Eram 15 professores que ministravam as 11 disciplinas que compunham o currículo das turmas-alvo.

\section{Materiais}

Para avaliar o processo, como pré e pós-testes, empregaramse uma Escala Likert de Atitudes em relação à Escolha Profissional (ELAEP) (Lamas, Pereira, \& Barbosa, 2008) e um questionário. Este instrumento possuía, no pré-teste, sete questões, englobando variáveis demográficas, segurança e preparação para realizar a escolha, acesso e busca de informações sobre profissões, profissões de interesse, e perguntas que avaliaram a participação dos docentes. Neste caso, havia uma questão com sete itens sobre atividades relacionadas à OP transversal ao currículo para que os alunos indicassem o número de professores que as realizaram. Destaca-se que, no pós-teste, foram suprimidas algumas perguntas do questionário, como as demográficas, uma vez que as respostas não mudariam no intervalo de tempo da OP ou são invariáveis. No pós-teste, esse instrumento teve cinco questões.

A ELAEP contém 36 itens, sendo que 16 descrevem atitudes positivas e 20, atitudes negativas. Trata-se de uma escala forçada, ou seja, sem possibilidade de indecisão e/ou neutralidade, com quatro pontos de resposta: (1) Concordo totalmente; (2) Concordo; (3) Discordo totalmente; ou (4) Discordo. Ao analisar os dados, é necessário inverter a pontuação dos itens positivos, de forma que maiores pontuações passem a refletir atitudes mais positivas em relação à escolha profissional. Esse instrumento foi elaborado a partir da revisão de literatura e, especialmente, de experiências anteriores com processos de OP.

Até o momento, só é possível pontuar a escala de acordo com o total, uma vez que não há uma estrutura fatorial validada. A pontuação é feita a partir da média geral de todos os itens que, por consequência, pode variar entre um - atitudes mais negativas - e quatro - atitudes mais positivas. Apesar de já ter sido usada como medida em outra orientação (Lamas, Pereira, \& Barbosa, 2008), não há, até o momento, evidências de validade. Assim, não é possível apresentar informações psicométricas dessa medida.

\section{Procedimento}

Para a implantação da OP transversal ao currículo, contou-se com o apoio dos coordenadores do ensino médio que permitiram a apresentação e a análise do trabalho em duas reuniões com os professores das três turmas do segundo ano. No primeiro dia da OP, informou-se aos alunos sobre a importância de sua participação, já que as atividades fariam parte do currículo. Também foram esclarecidos os aspectos éticos relacionados à investigação para, posteriormente, aplicar os instrumentos descritos no subitem Materiais (pré-teste).

O processo de OP transversal ao currículo durou dois meses. O planejamento das atividades transversais foi feito tendo como base os aspectos que contribuem para a escolha profissional, identificados em vários estudos com abordagens distintas (Bock, 2002; Jenschke, 2002; Lassance \& Sparta, 2003; Lent et al., 2002; Ribeiro, 2003; Uvaldo,1995) e nas diretrizes do MEC
(Parâmetros Curriculares Nacionais, 1998). No planejamento e na execução da OP transversal, esses aspectos foram organizados, desenvolvidos e interpretados com base na Teoria Sociocognitiva para o Desenvolvimento de Carreira e na Teoria Comunitária Emancipatória (Blustein et al., 2005). Propôs-se, com base nesse referencial, a seguinte estratégia de ação:

1. Semana das Profissões - O objetivo da semana foi aproximar os alunos do mundo profissional e acadêmico, e estreitar a relação professor-aluno a partir dos relatos pessoais efetuados pelos docentes, facilitando a definição de interesses e promovendo a valorização do currículo escolar e da experiência profissional e pessoal dos educadores.

2. O Trabalho no Cotidiano da Sala de Aula - Teve como objetivo inserir as questões do mundo do trabalho nas disciplinas ministradas no dia a dia da sala de aula, enfatizando a relação entre o conteúdo transmitido e sua influência na vida e nas escolhas dos alunos.

3. Cinema - Objetivou relacionar a escolha profissional com gênero, condições socioeconômicas e influência familiar e social. Posteriormente, houve um debate e a professora solicitou questões reflexivas em prova sobre o filme.

4. Redação - A atividade teve como objetivo promover a reflexão sobre as relações entre projeto vida e escolha profissional ,por meio de um texto produzido na disciplina de Língua Portuguesa.

Além dos professores, um dos autores participou ativamente em sala de aula. Foi realizado um trabalho interdisciplinar que abrangeu a preparação e a execução de aulas e atividades para facilitar o desenvolvimento vocacional.

No último dia, os instrumentos foram reaplicados (pós-teste). A primeira (pré-teste) e a segunda aplicação dos instrumentos foram realizadas em sala de aula e sem controle de tempo.

\section{Resultados}

Ao analisar a participação dos professores no projeto, constatou-se que o número de docentes que realizou atividades relacionadas ao trabalho e à escolha profissional de forma transversal ao currículo aumentou significativamente no pós-teste em seis das sete situações avaliadas: 1) Discutir as características - positivas e negativas - dos cursos de graduação que eles fizeram (Pré-teste: $\bar{X}=0,86 ; D P=1,25$. Pós-teste: $\bar{X}$ $\left.=1,97 ; D P=1,77 . t_{o}=-5,162 ; g l=63 ; p<0,001\right)$. 2) Refletir sobre as vantagens e desvantagens dos cursos de graduação e das profissões relacionados às disciplinas ministradas (Pré-teste: $\bar{X}=0,64 ; D P=1,08$. Pós-teste: $\bar{X}=2,01 ; \mathrm{DP}=2,14 . t_{o}=5,655$; $g l=64 ; p<0,001)$. 3) Discutir sobre o significado do trabalho para o ser humano (Pré-teste: $\bar{X}=1,55 ; D P=1,80$. Pós-teste: $\left.X=2,24 ; D P=2,82 . t_{o}=2,386 ; g l=65 ; p<0,05\right)$. 4) Analisar aspectos do mercado de trabalho atualmente (Pré-teste: $\bar{X}=$ 1,55; $D P=1,65$. Pós-teste: $\bar{X}=2,19 ; D P=2,12 . t_{o}=-2,728 ; g l$ $=64 ; p<0,01) .5)$ Refletir sobre o papel da mídia na escolha profissional (Pré-teste: $\bar{X}=0,61 ; D P=1,06$. Pós-teste: $\bar{X}=1,13$; $\left.\left.D P=1,71 . t_{o}=2,997 ; g l=64 ; p<0,01\right) .6\right)$ Apresentar e analisar características de profissões conhecidas por ele (Pré-teste: $\bar{X}=$ 1,07; $D P=1,73$. Pós-teste: $\bar{X}=1,82 ; D P=1,74 . t_{o}=-3,468$; 
$g l=64 ; p<0,01)$.

Isso só não ocorreu em um dos aspectos avaliados: relacionar a matéria com a prática profissional (Pré-teste: $\bar{X}=$ 1,$85 ; D P=2,85$. Pós-teste: $X=2,37 ; D P=2,03 . t_{o}=-1,368$; $g l=65 ; p>0,05)$. Entretanto, destaca-se que, para esse item, a quantidade média de professores era a mais alta do pré-teste.

Observa-se que as médias relativas aos professores que trabalhavam os temas de forma transversal ao currículo no pré-teste eram bastante baixas. No pós-teste houve aumento significante em quase todos os itens avaliados. Todavia, se for considerado o fato de que as turmas têm cerca de 10 professores, é possível afirmar que essas médias ainda continuam baixas.
Na Tabela 1 observam-se os resultados obtidos pré e pósorientação em relação ao comportamento vocacional dos alunos que participaram da OP transversal ao currículo. Ao comparar a quantidade de dúvidas sobre possíveis profissões de interesse dos participantes, constatou-se diferença significante $\left(t_{o}=2,934\right.$ $g l=62 ; p<0,01)$ com a redução do número de participantes que apresentaram muitas dúvidas pós-orientação. A análise do nível de escolaridade exigido para as profissões que foram mencionadas como primeira opção pelos participantes revelou que tanto no pré $\left(\chi_{0}^{2}=64,871 ; g l=2 ; p<0,01\right)$ quanto no pósteste $\left(\chi_{o}^{2}=67,968 ; g l=2 ; p<0,01\right)$ predominaram aquelas que exigiam curso superior.

\begin{tabular}{|c|c|c|c|c|}
\hline \multirow{2}{*}{ Variáveis } & \multicolumn{2}{|c|}{ Pré-teste } & \multicolumn{2}{|c|}{ Pós-teste } \\
\hline & $n$ & $\%$ & $n$ & $\%$ \\
\hline \multicolumn{5}{|c|}{ Dúvidas em relação às profisssões } \\
\hline Nenhuma dúvida ou dúvida mínima & 21 & 33,33 & 30 & 47,62 \\
\hline Algumas dúvidas & 20 & 31,75 & 21 & 33,33 \\
\hline Muitas dúvidas & 22 & 34,92 & 12 & 19,05 \\
\hline Total * & 63 & 100 & 63 & 100 \\
\hline \multicolumn{5}{|c|}{ Escolaridade exigida para as profissões de interesse } \\
\hline Educação Superior & 50 & 81,65 & 51 & 82,26 \\
\hline Ensino Médio & 1 & 1,61 & 2 & 3,23 \\
\hline Outros & 11 & 17,74 & 09 & 14,52 \\
\hline Total * & 62 & 100 & 62 & 100 \\
\hline \multicolumn{5}{|c|}{ Segurança para escolha profissional } \\
\hline Extremamente inseguro & 09 & 13,24 & 08 & 11,76 \\
\hline Inseguro & 34 & 50,00 & 31 & 45,59 \\
\hline Seguro & 18 & 26,47 & 20 & 29,41 \\
\hline Extremante seguro & 07 & 10,29 & 09 & 13,24 \\
\hline Total $*$ & 68 & 100 & 68 & 100 \\
\hline \multicolumn{5}{|c|}{ Preparação para a escolha profissional } \\
\hline Extremamente despreparado & 03 & 4,41 & 05 & 7,35 \\
\hline Despreparado & 35 & 51,47 & 29 & 42,65 \\
\hline Preparado & 25 & 36,76 & 29 & 42,65 \\
\hline Extremamente preparado & 05 & 7,35 & 05 & 7,35 \\
\hline Total * & 68 & 100 & 68 & 100 \\
\hline \multicolumn{5}{|c|}{ Busca de informação sobre profissões } \\
\hline Sim & 42 & 61,76 & 46 & 67,65 \\
\hline Não & 26 & 38,24 & 22 & 32,35 \\
\hline Total * & 68 & 100 & 68 & 100 \\
\hline \multicolumn{5}{|c|}{ Fontes de informação } \\
\hline Jornais e revistas & 08 & 19,05 & 05 & 10,87 \\
\hline Revistas ou manuais especializados & 08 & 19,05 & 14 & 30,44 \\
\hline Internet & 20 & 47,62 & 23 & 50,00 \\
\hline Jornais, revistas e Internet & 01 & 2,38 & 01 & 2,17 \\
\hline Manuais especializados e Internet & 05 & 11,90 & 03 & 6,52 \\
\hline Total & 42 & 100 & 46 & 100 \\
\hline
\end{tabular}

Em relação às variáveis que investigaram a percepção dos estudantes sobre segurança $\left(t_{o}=-1,123 ; g l=67 ; p=0,265\right)$ e preparação $\left(t_{o}=-0,331 ; g l=67 ; p=0,742\right)$ para a escolha profissional não foi encontrada diferença significante entre $o$ pré e o pós-teste. Contudo, observa-se uma variação positiva em ambas as medidas.
Algo similar ocorreu com a variável informação profissional (Tabela 1). Observa-se que a maioria dos alunos já procurava informação sobre profissões antes da intervenção $\left(\chi_{0}^{2}=3,765\right.$; $g l=1 p<0,05)$ e continuou fazendo isso pós-intervenção $\left(\chi_{o}^{2}\right.$ $=7,667 ; g l=1 ; p<0,01)$.

Ainda considerando a busca de informações, verificou-se 
que $54,41 \%(n=37)$ mantiveram esse comportamento pósorientação, 13,24\% $(n=9)$ passaram a fazer isso, $25 \%(n=22)$ continuaram a não buscá-las e $7,35 \%(n=5)$ passaram a não realizar buscas. $\mathrm{O}$ teste $\mathrm{Phi}(\mathrm{Phi}=0,556 ; p<0,00)$ revelou que a maioria dos participantes se concentrou no primeiro subgrupo, isto é, manutenção da busca por informações.

Verificou-se que o meio mais utilizado pelos adolescentes para coletar informações sobre profissões foi a Internet, tanto pré $\left(\chi_{o}^{2}=23,952 ; g l=4 ; p<0,01\right)$ quanto pós-intervenção $\left(\chi_{o}^{2}=\right.$ $36,609 ; g l=4 ; p<0,01)$. É preciso destacar, ainda, o aumento da quantidade de jovens que começaram a utilizar também fontes como revistas ou manuais especializados.

Não foram obtidas diferenças significantes no que se refere às atitudes em relação à escolha profissional pré e pósorientação $\left(t_{o}=-0,960 ; g l=68 ; p=0,340\right)$. Há que se retomar que a medida atitudinal foi efetuada por meio da ELAEP, e sua pontuação geral pode variar entre um - atitudes mais negativas - e quatro - atitudes mais positivas. Assim, as médias pré ( $\bar{X}=$ $2,75 ; D P=0,21)$ e pós-orientação $(\bar{X}=2,77 ; D P=0,20)$ podem ser consideradas indicadoras de atitudes positivas por parte dos alunos, pois se trata de uma escala "forçada". O instrumento, no entanto, não possui ainda ponto de corte.

Ao considerar as três turmas do segundo ano do ensino médio que participaram da OP transversal ao currículo, verificase que elas não diferiram no que se refere às atitudes em relação à escolha profissional pré $(F=0,689 ; p=0,505)$ e pós-orientação $(F=1,200 ; p=0,308)$. O mesmo ocorreu no caso da percepção dos estudantes em relação à segurança para escolha profissional (Pré-teste: $F=0,224 ; p=0,800$. Pós-teste: $F=1,790 ; p=0,175$ ) e da preparação para essa decisão (Pré-teste: $F=1,403 ; p=0,253$. Pós-teste: $F=0,195 ; p=0,824)$. Também não houve diferença entre as turmas em relação às dúvidas sobre possíveis profissões a serem escolhidas (Pré-teste: $F=0,711 ; p=0,495$. Pós-teste: $F=0,768 ; p=0,468)$. Não existiu, ainda, diferença entre as turmas na variável busca de informação profissional antes $\left(\chi_{0}^{2}\right.$ $=0,576 ; g l=2 ; p=0,750)$ e depois $\left(\chi_{o}^{2}=2,339 ; g l=2 ; p=\right.$ $0,311)$ da intervenção.

Entretanto, no caso da percepção das três turmas sobre a quantidade de professores que inserem o trabalho e a escolha profissional de forma transversal ao currículo pré e pósorientação, foram obtidas diferenças significantes no pré-teste para "refletir sobre as vantagens e desvantagens dos cursos de graduação e das profissões relacionados às disciplinas ministradas" $(F=6,381 ; p<0,01)$, "relacionar a matéria com a prática profissional de algumas profissões" $(F=3,227 ; p<0,05)$, "discutir sobre o significado do trabalho para o ser humano" $(F=3,646 ; p<0,05)$ e "apresentar e analisar características de profissões conhecidas por ele" $(F=3,263 ; p<0,05)$. No pósteste, a diferença entre as turmas ocorreu somente para "discutir sobre o significado do trabalho para o ser humano" ( $F=4,174 ; p$ $<0,05)$ e "refletir sobre o papel da mídia na escolha profissional" $(F=4,191 ; p<0,05)$.

\section{Discussão}

Os resultados relativos à quantidade de professores que passaram a inserir o trabalho e a escolha profissional de forma transversal ao currículo pós-orientação sugerem que, de modo geral, os objetivos dessa atividade foram atingidos, isto é, houve transversalização. Há que se reiterar que os temas transversais perpassam o currículo, abrangendo várias disciplinas (Parâmetros Curriculares Nacionais, 1998). Ao se envolver ativamente no desenvolvimento do comportamento vocacional dos discentes, o educador supera papéis tradicionais focados na transmissão de conteúdos estanques, pois permite ao aluno associar as aprendizagens escolares ao mundo do trabalho.

Não obstante o resultado estatisticamente significativo, a participação do corpo docente da escola-alvo no processo de OP transversal ao currículo deve melhorar muito mais, porque as turmas têm, pelo menos, uma dezena de professores, e a média de participação dos docentes ainda foi baixa. Dentre outras hipóteses para a pouca participação dos professores, menciona-se o fato de o projeto ter sido implantado no segundo semestre letivo. Além da interrupção das aulas por várias atividades extraclasses nesse período, havia a preocupação com o cumprimento do planejamento pedagógico antes das provas do vestibular seriado, que, naquele ano, ocorreriam no início de dezembro. Percebe-se que os professores ainda ficam presos aos conteúdos e às práticas pedagógicas tradicionais, o que é reforçado pela pressão decorrente das provas de ingresso em universidades, obstáculo para estimular o comportamento exploratório vocacional em escolas já destacado na literatura (Bardagi et al., 2003; Ribeiro, 2003; Sparta \& Gomes, 2005).

Ressalta-se, ainda, a necessidade de promover o envolvimento ativo da comunidade externa à escola. Há que buscar o engajamento de empresas, líderes comunitários e outras pessoas e instituições que sirvam como modelos e/ou fonte de suporte social para os jovens em fase de decisão profissional.

Apesar das limitações, a intervenção contribuiu para reduzir o número de possíveis profissões de interesse, indicando que houve auxílio na definição das preferências ocupacionais. Esse resultado deve ser interpretado com cautela, uma vez que não houve um grupo controle para comparação. Esse decréscimo pode ter sido decorrente de outras variáveis e não da OP.

O trabalho realizado teve como uma de suas prioridades o comportamento exploratório vocacional em relação às diversas profissões que demandam distintas formações. Dessa forma, a tomada de decisão quanto a uma profissão não foi prioridade porque os estudantes estavam no segundo ano do ensino médio. Mesmo assim, verificou-se que a maioria dos participantes mencionava inicialmente, como opções profissionais, carreiras que exigiam curso superior e continuaram fazendo isso, o que está em consonância com outras pesquisas que investigaram a pretensão de alunos após o ensino médio (p. ex.: Sparta \& Gomes, 2005). O Censo Demográfico de 2000, porém, revela que o ensino superior, tão apreciado pelos alunos, em grande parte dos casos não leva o jovem à atividade profissional desejada, ou seja, existe uma baixa relação entre curso superior efetuado e atividade profissional exercida (Nunes \& Carvalho, 2007). Mesmo que o mercado de trabalho valorize a educação superior, a falta dela não representa um obstáculo para a inserção nesse meio, porquanto a economia atual não se reduz às ocupações regulamentadas.

Não obstante os ganhos obtidos com a OP transversal, o 
programa não foi suficiente para provocar mudanças no que se refere às atitudes em relação à escolha e ao sentimento de preparação e à segurança para a escolha profissional. Isso pode ter ocorrido devido à elevada linha de base observada no préteste, ou seja, muitos estudantes já possuíam atitudes positivas e também altos níveis de preparação e segurança, o que torna mais difícil identificar efeitos positivos do trabalho. Além disso, a idade média da amostra estava em torno dos dezesseis anos. Baseando-se em uma perspectiva desenvolvimentista, pode-se inferir que, para muitos dos adolescentes, a questão profissional não era a preocupação principal (Bardagi et al., 2005). Ademais, os participantes possuíam, relativamente, bastante tempo para realizar a escolha e, provavelmente, não sentiam necessidade de se encontrarem dispostos para a decisão naquele momento. Há que se considerar, dessa forma, que a determinação para a escolha profissional se desenvolve ao longo do ensino médio (Neiva, 2003).

Além das hipóteses formuladas no parágrafo anterior para explicar a não alteração das atitudes em relação à escolha profissional, bem como a manutenção da percepção quanto aos níveis de segurança e preparação para esse processo, é possível que a OP tenha aumentado o nível de informação, sem, necessariamente, conseguir promover mudanças relacionadas às questões mais pessoais implicadas nas escolhas de cada aluno. Isso pode ter ocorrido em função de as atividades terem, predominantemente, um caráter global, de inserção do tema trabalho, mas sem abordar diretamente as dúvidas e questões particulares dos estudantes.

Também era característica da amostra antes da intervenção a busca por informação profissional e continuou sendo pós-OP. Isso é um sinal da presença de um comportamento exploratório vocacional em desenvolvimento. Isso é alentador, uma vez que várias pesquisas indicam que a evasão universitária se dá pela falta de informação sobre o curso e características da profissão (Bardagi et al., 2003; Lehman, 2005). No entanto, mesmo com uma tendência ao aumento do uso de fontes como revistas e manuais especializados, verificou-se que o meio mais utilizado foi a Internet, o que pode permitir o acesso a informações pouco confiáveis.

Apesar da ausência de significância estatística, observouse uma mudança referente à investigação ocupacional após a orientação. Alguns alunos que não procuravam conhecimento antes da intervenção estavam fazendo isso ao final do processo, enquanto outros, que as buscavam, pareciam ter finalizado sua pesquisa. Talvez os primeiros tenham despertado o interesse pela escolha da profissão, ao passo que os últimos podem ter colhido informações suficientes para a tomada de decisão, denotando diferentes níveis de maturidade para escolha profissional, como analisado por Bardagi et al. (2005) e Neiva (2003).

Em síntese, os alunos tanto no pré quanto no pós-teste possuíam atitudes positivas, sentiam-se seguros e preparados para escolha e buscavam informação. Contudo, no pós-teste, delimitaram mais as carreiras que pretendiam seguir. Assim, pode-se afirmar que o projeto favoreceu a aprendizagem dos processos envolvidos na escolha (Bock, 2002; Carvalho, 1995; Sparta, 2003), estimulando o autoconhecimento e comportamentos fundamentais para o desenvolvimento de um projeto profissional. É provável que a intervenção tenha gerado nos participantes maior reflexão sobre aspectos pessoais e sociais e limitações envolvidos na escolha de uma profissão (Sparta et al., 2006), e promovido a capacidade de reconhecer as expectativas futuras, os interesses e as habilidades pessoais (Bardagi et al., 2005).

Divergindo do que é tradicional, a OP efetuada para atingir os resultados analisados no parágrafo anterior teve caráter educativo e não clínico, de promoção de desenvolvimento e não de atuar em momentos críticos. Orientações voltadas para a vida profissional com esse caráter não têm sido o foco de pesquisas nos últimos anos. No Brasil, comumente, o que se aplica é o modelo clínico. Essa abordagem, porém, atinge apenas parte da população de jovens, normalmente estudantes de escolas particulares que se interessam por carreiras universitárias e estão próximos de realizar o vestibular (Melo-Silva et al., 2004; Ribeiro, 2003).

Para atingir um público mais abrangente e atuar de forma preventiva, esta pesquisa com intervenção articulou profissão e escolhas de forma educativa, transversalmente às disciplinas escolares, com a participação ativa dos professores, baseando-se na Teoria Sociocognitiva para o Desenvolvimento de Carreira e na Teoria Comunitária Emancipatória como proposto por Blustein et al. (2005). Geralmente, quando a OP acontece na escola, é realizada por profissionais especializados, como psicólogos ou pedagogos (Melo-Silva et al., 2004). De forma transversal, ela pode ser muito mais rica, distribuindo o conhecimento de forma igualitária e possibilitando uma reflexão que aspira à emancipação (Prilleltensky, 1997).

A transversalidade é um desafio, visto que pede uma transformação da atividade pedagógica formal e, ainda, que os temas sejam trabalhados em todas as disciplinas ao longo dos anos escolares (Bovo, 2004). No entanto, a OP realizada, ao mesmo tempo em que se faz inovadora, apresenta várias limitações concernentes a uma efetiva transversalidade, porque a participação dos docentes foi pequena, a duração do projeto foi limitada e a interdisciplinaridade ocorreu de forma restrita, limitando-se à colaboração entre Psicologia e disciplinas do currículo, sem haver um diálogo e, especialmente, uma ação conjunta de professores. Ainda assim, os resultados obtidos revelaram, de forma sutil e inicial, que a inserção do trabalho e da escolha profissional transversal ao planejamento pedagógico é viável e representa uma possibilidade de favorecer o desenvolvimento vocacional dos adolescentes.

\section{Referências}

Abade, F. L. (2005). Orientação profissional no Brasil: uma revisão histórica da produção científica. Revista Brasileira de Orientação Profissional, 6(1), 15-24.

Affonso, R. M. L., \& Sposito, L. L. (2005). Oficinas de orientação profissional no contexto escolar: a construção de um modelo. In M. C. P. Lassance, A. C. Paradiso, M. P. Bardagi, M. Sparta \& S. L. Frischenbruder (Orgs.), Intervenção e compromisso social (pp.173-184 ). São Paulo: Vetor.

Antunes, D. C., Castro, A. B., Garbulho, N. F., \& Oliveira, E. C. S. (2007) Orientação profissional na educação pré-escolar: livros, teatro, vídeos e histórias infantis como instrumentos para um trabalho reflexivo. In M. T. Lima, D. T. R. Barros \& R. Escalda (Orgs.), Escolha e inserção profissionais: 
desafios para individuos, famílias e instituições (pp. 225-240). São Paulo: Vetor.

Bardagi, M. P., Arteche, A. X., \& Neiva-Silva, L.(2005). Projetos sociais com adolescentes em situação de risco: discutindo o trabalho e a orientação profissional como estratégias de intervenção. In C. Hutz (Org.), Violência e risco na infância e na adolescência: pesquisa e intervenção (pp. 101-146). São Paulo: Casa do Psicólogo.

Bardagi, M. P., Lassance, M. C. P., \& Paradiso, A. C. (2003). Trajetória acadêmica e satisfação com a escolha profissional de universitários em meio de curso. Revista Brasileira de Orientação Profissional, 4(2), 153-166.

Blustein, D. L., McWhirter, E. H., \& Perry, J. C. (2005). An emancipatory communitarian approach to vocational development: theory, research, and practice. The Counseling Psychologist, 33(2), 141-179.

Bock, A. M. B., \& Aguiar, W. M. J. (1995). Por uma prática promotora de saúde em orientação vocacional. In A. M. Bock et al. (Orgs.), A escolha profissional em questão (pp. 9- 23). São Paulo: Casa do Psicólogo.

Bock, S. D. (2002). Orientação profissional: a abordagem sócio-histórica. São Paulo: Cortez.

Bohoslavsky, R. (1993). Orientação vocacional: a estratégia clínica ( $9^{\underline{a}}$ ed.). São Paulo: Martins Fontes.

Bovo, M. C. (2004). Interdisciplinaridade e transversalidade como dimensões da ação pedagógica. Revista Urutágua, 07. Recuperado de http://www. urutagua.uem.br

Carvalho, M. M. J. (1995). Orientação profissional em grupo: teoria e técnica. São Paulo: Editorial Psy II.

Jenschke, B. (2002). Educação profissional em escolas em uma perspectiva internacional. In R. S. Levenfus \& D. H. P. Soares (Orgs.), Orientação vocacional ocupacional: novos achados teóricos, técnicos e instrumentos para a clínica, escola e a empresa (pp. 23-31). Porto Alegre: Artmed.

Lamas, K. C. A., Pereira, S. M., \& Barbosa, A. J. G. (2008). Orientação profissional na escola: uma pesquisa com intervenção. Psicologia em Pesquisa, 2(1), 60-68.

Lassance, M. C. \& Sparta, M. (2003). A orientação profissional e as transformações no mundo do trabalho. Revista Brasileira de Orientação Profissional, 4(1/2), 13-19.

Lehman, Y. P. (1995). O papel do orientador profissional - revisão crítica. In A M. B. Bock et al. (Org.) A escolha profissional em questão (pp. 239-247). São Paulo: Casa do Psicólogo.

Lehman, Y. P. (2005, outubro 18). Má escolha é a maior causa de evasão. Folha de São Paulo, São Paulo, p. 06-07. Recuperado de http://www1.folha.uol.com.br

Lei n. 9.394, de 20 de dezembro de 1996. (1996, 23 de dezembro). Estabelece as diretrizes e bases da educação nacional. Recuperado de www.planalto.gov. br/ccivil_03/LEIS/19394.htm

Lent, R. W., Brown, S. D., Talleyrand, R., McPartland, E. B., Davis, T., Chopra, ... Chai, C. M. (2002). Career choice barriers, supports, and coping strategies: college students' experiences. Journal of Vocational Behavior, 60, 61-72 .

Melo-Silva, L. L., Lassance, M. C. P., \& Soares, D. H. P. (2004). A orientação profissional no contexto da educação e trabalho. Revista Brasileira de Orientação Profissional, 5(2), 31-52.

Neiva, K. M. C. (2003). A maturidade para a escolha profissional: uma comparação entre alunos do ensino médio. Revista Brasileira de Orientação Profissional,
4(1/2), 97-103.

Noronha, A. P. P., Freitas, F. A., \& Ottati, F. (2003). Análise de instrumentos de avaliação de interesses profissionais. Psicologia: Teoria e Pesquisa, 3(19), 287-291.

Nunes, E., \& Carvalho, M. M. (2007). Ensino universitário, corporação e profissão: paradoxos e dilemas brasileiros. Sociologias, 9(17), 190-215.

Parâmetros Curriculares Nacionais: terceiro e quarto ciclos (1998) Apresentação dos temas transversais. Brasília, DF: Ministério da Educação.

Pasqualini, J. C., Garbulho, N. F., \& Schut, T. (2004). Orientação profissional com crianças: uma contribuição à educação infantil. Revista Brasileira de Orientação Profissional, 5(1), 71-85.

Pelletier, D. (1981). Desenvolvimento vocacional e crescimento pessoal. Petrópolis, RJ: Vozes.

Prilleltensky, I. (1997). Values, assumptions, and practices assessing the moral implications of psychological discourse and action. American Psychologist, 52(5), 517-535

Ribeiro, M. A. (2003). Demandas em orientação profissional: um estudo exploratório em escolas públicas. Revista Brasileira de Orientação Profissional, 4(1/2), 141-151

Robitschek, C., \& Woodson, S. J. (2006). Vocational psychology: using one of counseling psychology's strengths to foster human strength. The Counseling Psychologist, 34(2), 260-275

Silva, I. C. T., \& Birk, C. (2002). Um modelo de atendimento em orientação profissional na escola privada. In R. S. Levenfus \& D. H. P. Soares (Orgs.), Orientação vocacional ocupacional: novos achados teóricos, técnicos e instrumentos para a clínica, escola e a empresa (pp. 101-114). Porto Alegre: Artmed.

Southern Regional Education Board - SREB. (2005). Helping students make good decisions and act on them: the real meaning of guidance and advisement. Best practices for implementing HSTW and MMGW.

Souza, A. M. O., Toledo, L. C. C., Martins, A. N., \& Vardi, C. H. G. R. (2004). Olhando para o futuro: orientação profissional na grade curricular. In Z . B. Vasconcellos \& I. D. Oliveira (Orgs.), Orientação vocacional: alguns aspectos teóricos, técnicos e práticos, (pp.187-198). São Paulo: Vetor.

Sparta, M. (2003). O desenvolvimento da orientação profissional no Brasil. Revista Brasileira de Orientação Profissional, 4(1/2), 1-11.

Sparta, M. \& Gomes, W. B.(2005). Importância atribuída ao ingresso na educação superior por alunos do ensino médio. Revista Brasileira de Orientação Profissional, 6(2), 45-53.

Sparta, M., Bardagi, M. P., \& Teixeira, M. A. P. (2006). Modelos e instrumentos de avaliação em orientação profissional: perspectiva histórica e situação no Brasil. Revista Brasileira de Orientação Profissional, 7(2), 45-53.

Uvaldo, M. C. C. (1995). Relação homem-trabalho: campo de estudo e atuação da orientação profissional. In A. M. B. et al.(Orgs.), A escolha profissional em questão (pp. 215-237). São Paulo, SP: Casa do Psicólogo.

Valore, L.A. (2002). Orientação profissional em grupo na escola pública. Direções possíveis, desafios necessários. In R. S. Levenfus \& D. H. P. Soares (Orgs.), Orientação vocacional ocupacional: novos achados teóricos, técnicos e instrumentos para a clínica, escola e a empresa (pp. 115-131). Porto Alegre: Artmed.

Altemir José Gonçalves Barbosa, doutor em Psicologia pela Pontifícia Universidade Católica de Campinas, é professor do departamento de Psicologia da Universidade Federal de Juiz de Fora. Endereço para correspondência: Pós-Graduação em Psicologia - ICH, Universidade Federal de Juiz de Fora, Rua José Lourenço Kelmer, s/n - Campus Universitário, Bairro São Pedro, Juiz de Fora, MG. CEP: 36036-900. Telefone: (32) 2102-3103. Fax: (32) 3217-8253. Email: E-mail: altgonc@gmail.com Karen Cristina Alves Lamas, mestre em Psicologia pela Universidade Federal de Juiz de Fora, é doutoranda em Psicologia pela Universidade São Francisco. E-mail: karen_lammas@yahoo.com.br 